\title{
A potential therapy for chordoma via antibody-dependent cell-mediated cytotoxicity employing NK or high-affinity NK cells in combination with cetuximab
}

\author{
Rika Fujii, MD, PhD, Jeffrey Schlom, PhD, and James W. Hodge, PhD, MBA \\ Laboratory of Tumor Immunology and Biology, Center for Cancer Research, National Cancer Institute, National Institutes of \\ Health, Bethesda, Maryland
}

\begin{abstract}
OBJECTIVE Chordoma is a rare bone tumor derived from the notochord and is resistant to conventional therapies such as chemotherapy, radiotherapy, and targeting therapeutics. Expression of epidermal growth factor receptor (EGFR) in a large proportion of chordoma specimens indicates a potential target for therapeutic intervention. In this study the authors investigated the potential role of the anti-EGFR antibody cetuximab in immunotherapy for chordoma.
\end{abstract}

METHODS Since cetuximab is a monoclonal antibody of the $\lg G 1$ isotype, it has the potential to mediate antibody-dependent cell-mediated cytotoxicity (ADCC) employing natural killer (NK) cells as effectors. Polymorphisms in the CD16 allele expressed on NK cells have been shown to influence the degree of ADCC of tumor cells, with the high-affinity valine (V)/V allele being responsible for more lysis than the V/phenylalanine (F) or FF allele. Unfortunately, however, only approximately $10 \%$ of the population expresses the VV allele on NK cells. An NK cell line, NK-92, has now been engineered to endogenously express IL-2 and the high-affinity CD16 allele. These irradiated high-affinity (ha)NK cells were analyzed for lysis of chordoma cells with and without cetuximab, and the levels of lysis observed in ADCC were compared with those of NK cells from donors expressing the VV, VF, and FF alleles.

RESULTS Here the authors demonstrate for the first time 1) that cetuximab in combination with NK cells can mediate ADCC of chordoma cells; 2) the influence of the NK CD16 polymorphism in cetuximab-mediated ADCC for chordoma cell lysis; 3) that engineered haNK cells - that is, cells transduced to express the CD16 V158 FcyRIIla receptor-bind cetuximab with similar affinity to normal NK cells expressing the high-affinity VV allele; and 4) that irradiated haNK cells induce ADCC with cetuximab in chordoma cells.

CONCLUSIONS These studies provide rationale for the use of cetuximab in combination with irradiated haNK cells for therapy for chordoma.

https://thejns.org/doi/abs/10.3171/2017.1.JNS162610

KEY WORDS chordoma; antibody-dependent cell-mediated cytotoxicity; ADCC; epidermal growth factor receptor; EGFR; cetuximab; immunotherapy; oncology

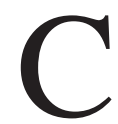
HORDOMA, a rare bone tumor, is derived from residual notochord. It accounts for $20 \%$ of primary spinal tumors and only $1 \%-4 \%$ of all malignant bone tumors. Approximately 300 new chordoma cases per year are diagnosed in the US, ${ }^{7,42}$ with approximately 2400 chordoma patients alive in the US annually. Median overall survival from the time of diagnosis is an estimated 6-7 years. ${ }^{24}$ Surgery followed by radiation therapy is the usual "standard of care," but the anatomical location and size of the tumor often prevent curative excision with clear margins. Thus, relapse is common and metastases have been reported in up to $40 \%$ of cases. The US Food and Drug Administration has approved no therapeutic agent for chordoma, and the disease entity is largely resistant to standard cytotoxic chemotherapy, ${ }^{36}$ creating an urgent need for novel therapeutic modalities.

Cytotoxic chemotherapy's ineffectiveness in chordoma has spurred efforts to identify new therapeutic modalities. mTOR, b-type platelet-derived growth factor receptor, vascular endothelial growth factor, and epidermal growth factor receptor (EGFR) have been identified as potentially relevant therapeutic targets for chordoma. ${ }^{17}$ Previous stud-

ABBREVIATIONS ADCC = antibody-dependent cell-mediated cytotoxicity; EGFR = epidermal growth factor receptor; $\mathrm{E} / \mathrm{T}$ ratio $=$ effector cell/target cell ratio; $\mathrm{F}=$ phenylalanine; FITC = fluorescein isothiocyanate; haNK = high-affinity natural killer; $\mathrm{mAb}=$ monoclonal antibody; $\mathrm{MFI}=$ mean fluorescence intensity; NK = natural killer; PBMC = peripheral blood mononuclear cell; $\mathrm{PCR}=$ polymerase chain reaction; $\mathrm{V}=$ valine.

SUBMITTED October 20, 2016. ACCEPTED January 26, 2017.

INCLUDE WHEN CITING Published online July 28, 2017; DOI: 10.3171/2017.1.JNS162610. 
ies have shown that a large proportion of chordomas express EGFR. ${ }^{34,37,43}$ Cetuximab, an IgG1 anti-EGFR monoclonal antibody $(\mathrm{mAb})$, is the only anti-EGFR agent that both blocks the EGFR-dependent proliferation pathway and has the potential to induce antibody-dependent cellmediated cytotoxicity (ADCC). ${ }^{12}$ In in vitro studies, cetuximab mediated ADCC in several types of cancer cells that express EGFR, including esophageal cancer, nonsmall cell lung cancer, and squamous cell carcinoma of the head and neck. ${ }^{26}$ Several therapeutic agents targeting EGFR, including erlotinib, gefitinib, lapatinib, and sapatinib, have been shown to inhibit the proliferation of chordoma cells..$^{33,35}$ To date, however, the use of radiation and/ or these and other agents has resulted in an extremely low response rate in patients, that is, less than 5\%. The potential of cetuximab-mediated ADCC in chordoma has not been investigated.

Antibody-dependent cell-mediated cytotoxicity is mediated by the binding of a human IgG1 antibody with its ligand on tumor cells and with the CD16 Fc receptor on natural killer (NK) cells. Interaction between IgG1 antibody-bound tumor cells and Fc $\gamma$ receptor triggers the activation and degranulation of the NK cells (Fig. 1). Natural killer cells from healthy donors can express 3 types of polymorphism in the CD16 allele: 1) endogenous alleles for the CD16 high-affinity Fc receptor Fc $\gamma$ RIIIa (V158) only (VV genotype), 2) endogenous alleles for the loweraffinity phenylalanine (F) allele only (FF genotype), or 3) both alleles (VF genotype). In general, the NK cells of the VV allele are the most efficient effectors in ADCC. Unfortunately, only approximately $14 \%$ of humans express the VV allele on NK cells. ${ }^{8,25,29,30,40,44,45}$ An NK cell line derived from a lymphoma patient has been shown, as an irradiated, adoptively transferred agent, to be safe and has provided preliminary evidence of clinical benefit. ${ }^{2,15,39}$ The NK-92 cell line, however, does not express CD16 and also requires IL-2 for propagation. This cell line has now been engineered to express the high-affinity (ha) CD16 V158 Fc $\gamma$ RIIIa receptor, as well as further engineered to express IL-2, and is designated haNK..$^{14}$

Here we demonstrate for the first time 1) that cetuximab in combination with NK cells can mediate ADCC of chordoma cells; 2) the influence of the NK CD16 polymorphism in cetuximab-mediated ADCC for chordoma cell lysis; 3) that engineered haNK cells - that is, cells transduced to express the CD16 V158 Fc $\gamma$ RIIIa receptor-bind cetuximab with similar affinity to normal NK cells expressing the high-affinity VV allele; and 4) that irradiated haNK cells induce ADCC with cetuximab in chordoma cells. Our findings suggest that while chordoma responds poorly to conventional therapies, the combination of adoptively transferred, irradiated haNK cells plus cetuximab may have clinical benefit for chordoma patients (Fig. 1).

\section{Methods \\ Cell Culture and Reagents}

The chordoma cell lines JHC7 and UM-Chor1 were obtained from the Chordoma Foundation. The chordoma cell lines U-CH2 (ATCC CRL-3218) and MUG-Chorl (ATCC CRL-3219) were obtained from American Type Culture
Collection. All cell lines were passaged for fewer than 6 months and were maintained as previously described. ${ }^{11}$ The haNK cells were provided through a Cooperative Research and Development Agreement (CRADA) between the National Cancer Institute and NantBioScience. The haNK cells were cultured in phenol red-free and gentamycin-free X-Vivo 10 medium (Lonza) supplemented with $5 \%$ heat-inactivated human AB serum (Omega Scientific Inc.) at a concentration of $5 \times 10^{5} / \mathrm{ml}$. Twenty-four hours before all experiments, the haNK cells were irradiated at 10 Gy. Peripheral blood mononuclear cells (PBMCs) from healthy volunteer donors were obtained from the National Institutes of Health Clinical Center Blood Bank (NCT00001846).

\section{Flow Cytometry}

The following anti-human mAbs were used: phycoerythrin (PE)-EGFR (BD Biosciences), fluorescein isothiocyanate (FITC)-CD16 clone 3G8 (BD Biosciences), allophycocyanin (APC)-CD56 (BioLegend), PE-CD226 (DNAM-1; BD Biosciences), PerCP-Cy5.5-NKG2D (BD Biosciences), and PE-Cy7-perforin (eBioscience). Samples were acquired on a FACSCalibur or FACSVerse flow cytometer (both Becton Dickinson) and analyzed using FlowJo software (TreeStar Inc.). Isotype control staining was $<5 \%$ for all samples analyzed.

\section{Antibody-Dependent Cellular Cytotoxicity Assay}

The ADCC assay was performed as previously described, ${ }^{5}$ with indicated modifications. Natural killer effector cells were isolated from healthy donor PBMCs using the human NK Cell Isolation Kit (negative selection, Miltenyi Biotec) according to the manufacturer's protocol, resulting in $>80 \%$ purity, and were allowed to rest overnight in RPMI-1640 medium containing 10\% fetal bovine serum. Tumor cells were harvested and labeled with ${ }^{111} \mathrm{In}$. Cells were plated as targets at 2000 cells/well in 96-well round-bottom culture plates and incubated with $10 \mu \mathrm{g} / \mathrm{ml}$ of cetuximab (Erbitux, Eli Lilly) or unresponsive rituximab (Rituxan, Biogen) as a control isotype antibody at room temperature for 30 minutes. Either NK cells or haNK cells were added as effector cells. Various effector cell/target cell $(\mathrm{E} / \mathrm{T})$ ratios were used in the study. After 4 or 20 hours, supernatants were harvested and analyzed for the presence of ${ }^{111} \mathrm{In}$ using a WIZARD2 Automatic Gamma Counter (PerkinElmer Inc.). Spontaneous release was determined by incubating target cells without effector cells, and complete lysis was determined by incubation with $0.05 \%$ Triton X-100 (Sigma-Aldrich Co.). Experiments were performed in triplicate. Specific ADCC lysis was determined using the following equation, where cpm stands for counts per minute: percent lysis $=[$ (experimental cpm - spontaneous cpm)/(complete cpm - spontaneous $\mathrm{cpm})] \times 100$.

To verify that CD16 (FcrRIII) on NK cells engages ADCC lysis mediated by cetuximab, CD16 mAb was used to block CD16. The NK cells were incubated with $2 \mu \mathrm{g} / \mathrm{ml}$ of CD16 mAb (clone B73.1, eBioscience) and haNK cells were incubated with $50 \mu \mathrm{g} / \mathrm{ml}$ of CD16 mAb, for 2 hours before being added to target cells. 

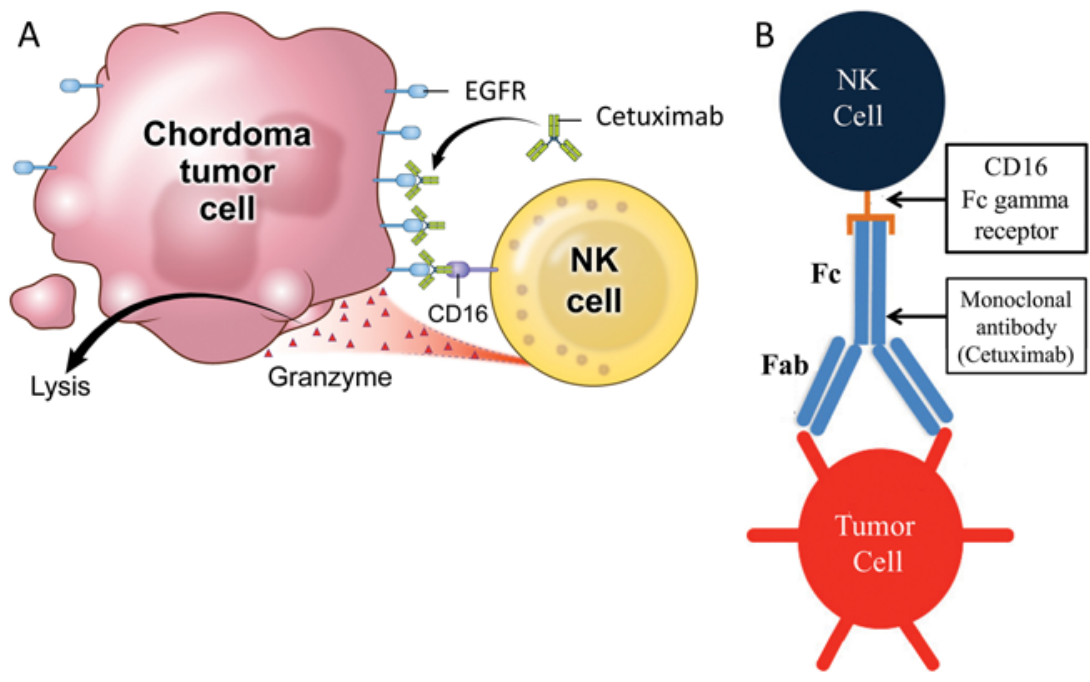

\begin{tabular}{|c|c|c|c|}
\hline & CD16 & Frequency (\%) & Affinity \\
\hline \multirow{3}{*}{ NK } & VV & $14 \pm 3$ & +++ \\
\hline & VF & $43 \pm 2$ & ++ \\
\hline & $\mathrm{FF}$ & $39 \pm 3$ & + \\
\hline haNK & V & & +++ \\
\hline
\end{tabular}

FIG. 1. Model of proposed mechanism of NK cell-mediated ADCC. A: Chordoma cells express EGFR. The anti-EGFR mAB cetuximab (human IgG1) binds EGFR. B: The Fc portion of the cetuximab is bound by the CD16 receptor of NK cells, forming a bridge that triggers granzyme degranulation and chordoma cell lysis (A). C: Patient NK cells express polymorphic CD16 receptors that bind antibody Fc at different affinities. The strongest CD16 affinity, VV, is seen in 14\% of the population, while the lower-affinity CD16 receptors VF and FF are seen in 82\% of the population. To compensate for potentially lower-affinity CD16 receptor-bearing endogenous NK cells, haNK cells (NK cells engineered to express high-affinity CD16 receptor and IL-2) can be infused into patients.

\section{CD16 (FcyRllla) Genotyping}

DNA was extracted from PBMCs of healthy donors using a QIAamp DNA Blood Mini Kit (Qiagen) and stored at $-80^{\circ} \mathrm{C}$ until use. The polymorphism of $\mathrm{CD} 16$ that is a valine $(\mathrm{V})$ versus phenylalanine $(\mathrm{F})$ substitution at amino acid position 158 was determined using allele-specific droplet digital polymerase chain reaction (PCR) employing the TaqMan array for CD16 (Life Technologies). ${ }^{23,25,31}$ A master reaction mix was prepared, and $1 \mu l$ of genotyping DNA was added. The PCR reaction was performed on a Bio-Rad T100 thermal cycler (Bio-Rad Laboratories) for 40 cycles at $95^{\circ} \mathrm{C}$ for 10 minutes, $94^{\circ} \mathrm{C}$ for 30 seconds, and $60^{\circ} \mathrm{C}$ for 1 minute. The plate was read on a Bio-Rad QX200 droplet reader. Data were analyzed with Bio-Rad QuantaSoft software version 1.5.

\section{Cetuximab-Binding Properties of FcyRIlla}

Cetuximab-binding properties of FcyRIIIa were examined as previously reported, ${ }^{8}$ with indicated modifications. Natural killer cells or haNK cells were incubated with varying concentrations of cetuximab at $4^{\circ} \mathrm{C}$ for 30 minutes. Cells were then incubated with FITC-conjugated $\mathrm{CD} 163 \mathrm{G} 8$ at $4^{\circ} \mathrm{C}$ for 30 minutes, washed twice with $1 \%$ bovine serum albumin/phosphate-buffered saline, and analyzed by flow cytometry. Results were expressed as the percentage inhibition of CD16 3G8 binding: (MFI in the absence of cetuximab - MFI in the presence of cetuximab) $\times 100 /($ MFI in the absence of cetuximab), where MFI represents mean fluorescence intensity.

\section{Statistical Analysis}

Significant differences in the distribution of data acquired by ADCC assays were determined by paired Student t-test with a 2-tailed distribution and reported as $\mathrm{p}$ values, using Prism 6.0f software (GraphPad Software Inc.). A $\mathrm{p}$ value $<0.05$ was significant.

\section{Results}

\section{Cetuximab Increases NK Cell Lysis of Chordoma Cell Lines via ADCC}

It has been shown that chordoma cell lines express EGFR. ${ }^{33}$ We qualitatively confirmed and extended this finding employing 4 human chordoma cell lines: JHC7, UM-Chorl, U-CH2, and MUG-Chorl (Fig. 2). The 4 chordoma cell lines expressed between $13 \%$ and $80 \%$ EGFR as determined by flow cytometry, although the absolute expression levels of EGFR can modulate with tissue culture density and time in culture.

We next performed an in vitro assay to determine cetuximab-mediated ADCC in chordoma cell lines employing NK cells from healthy donors as effectors. As shown in Fig. 3A, cetuximab significantly increased NK cell lysis relative to the isotype control antibody in $\mathrm{JHC} 7$ cells (13.7-fold, $\mathrm{p}<0.01$ ), UM-Chorl cells (10.5-fold, $\mathrm{p}<0.01$ ), U-CH2 cells (83.5-fold, $\mathrm{p}<0.01$ ), and MUG-Chor1 cells (59-fold, $\mathrm{p}<0.01$ ). Cetuximab alone (no NK cells) did not mediate lysis of chordoma cells (data not shown). Natural killer cell lysis via ADCC occurs when CD16 (FcyRIII) on NK effector cells interacts with the Fc portion of antibodies recognizing target cells (Fig. 1). ${ }^{1}$ As shown in Fig. $3 \mathrm{~B}$, the addition of CD16 neutralizing antibody inhibited cetuximab-enhanced NK cell lysis in both the JHC7 and UM-Chorl cell lines analyzed, indicating that cetuximabinduced NK cell lysis was mediated by ADCC.

\section{CD16 Polymorphism of NK Cells is Associated With Cetuximab-Mediated ADCC of Chordoma Cells}

The CD16 (Fc $\gamma$ RIIIa) polymorphism expressed on NK 


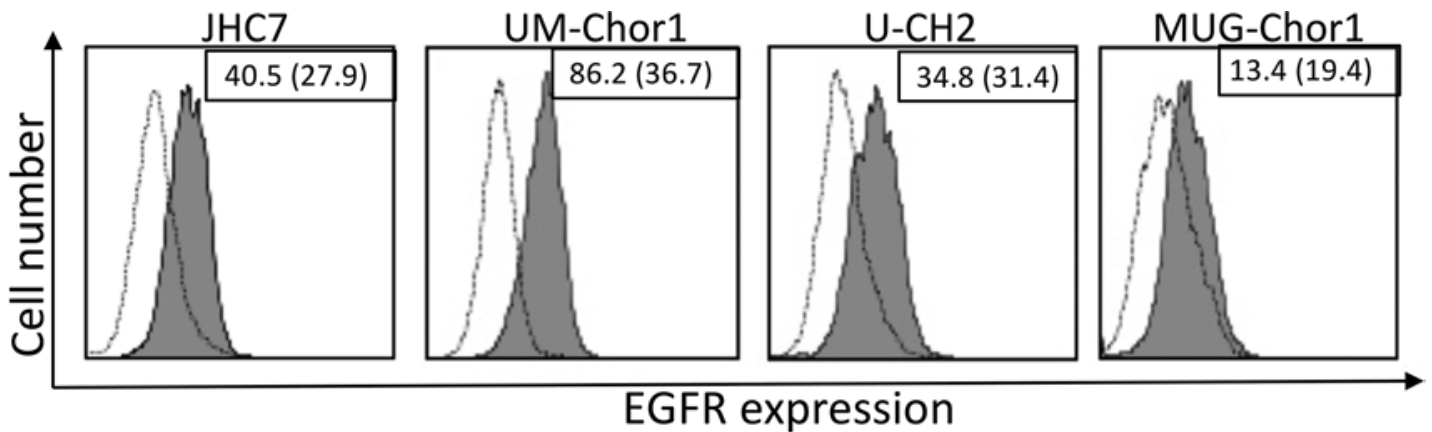

FIG. 2. Expression of EGFR in chordoma cell lines. Inset numbers indicate the percentage of positive cells (mean fluorescence intensity $[\mathrm{MFI}]$ ).

cells is associated with affinity of CD16 for IgG1 mAbs (Fig. 1). ${ }^{8,16}$ The FCGR3A gene, which encodes Fc $\gamma$ RIIIa, displays a functional allelic dimorphism that generates allotypes with either an $\mathrm{F}$ or a $\mathrm{V}$ residue at amino acid position $158 .{ }^{31}$ Previous studies have shown that the magnitude of response to cetuximab-mediated ADCC is related to FcyRIIIa polymorphism of NK cells in head and neck squamous cell carcinoma cells. ${ }^{21,38}$ We performed in vitro assays for ADCC activity mediated by cetuximab using FCGR3A-genotyped healthy-donor NK cells that expressed the FcyRIIIa-158 FF, VF, or VV allele. With the control isotype antibody, UM-Chorl cells were killed at
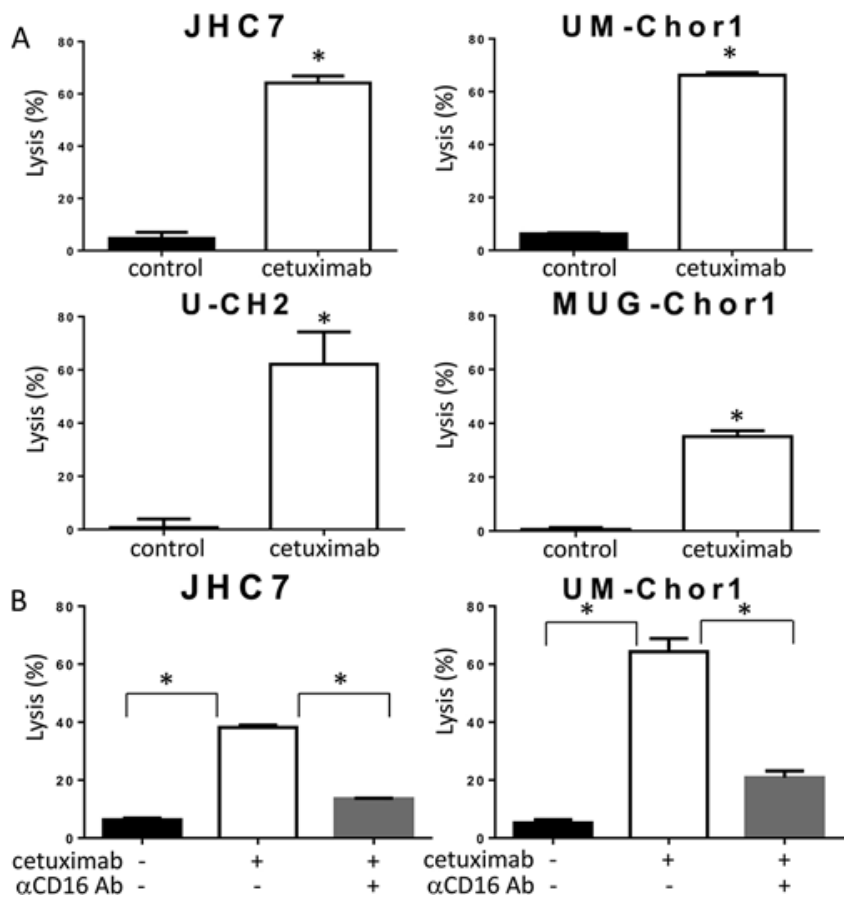

FIG. 3. Cetuximab increased NK cell lysis via ADCC in chordoma cell lines. A: The ADCC assays were performed using 4 chordoma cell lines, with healthy-donor NK cells at an E/T ratio of 20:1. Indicated groups were incubated with cetuximab. B: The ADCC assays were performed using 2 chordoma cell lines, with normal-donor NK cells at an $E / T$ ratio of 20:1. Indicated groups were incubated with cetuximab and anti-CD16 antibody (Ab). ${ }^{*} p<0.01$, Student t-test. Error bars indicate the mean \pm standard deviation for triplicate measurements. This experiment was repeated at least 2 times with similar results. very low levels by NK cells regardless of NK phenotype (Fig. 4A). However, cetuximab increased NK cell lysis in all the NK cell phenotypes. Cetuximab-induced lysis by NK cells from 3 donors expressing the FcyRIIIa-158 FF allele was $24 \%, 17 \%$, and $15 \%$, respectively. In contrast, cetuximab-induced ADCC lysis by NK cells using $3 \mathrm{VF}$ donors was $34 \%, 49 \%$, and $32 \%$, respectively, and $51 \%$, $66 \%$, and $59 \%$ lysis, respectively, using NK cells from 3 VV donors. There was a significant positive correlation $\left(\mathrm{R}^{2}=0.85\right)$ for the mean of cetuximab-mediated ADCC lysis induced by NK cells from 3 FF (19\%), 3 VF (38\%), and $3 \mathrm{VV}(59 \%)$ donors (Fig. 4B). Taken together, these results suggest that NK cells that express the Fc $\gamma$ RIIIa-158 $\mathrm{V}$ allotype exhibit enhanced cetuximab-mediated ADCC in chordoma cells.

\section{Phenotype of CD16 Polymorphism-Genotyped NK Cells and haNK Cells}

Natural killer cells from some individuals can be potent cytotoxic effectors for cancer therapy. However, there can be technical challenges in obtaining sufficient numbers of functionally active NK cells from patients. As an alternative, several cytotoxic NK cell lines have been generated, including NK-92. These NK-92 cells have recently been engineered to endogenously express IL-2 and haNK cells. ${ }^{14,15}$ We compared the phenotype (CD56, DNAM-1, NKG2D, perforin, and CD16) of CD16 polymorphismgenotyped healthy-donor NK cells with that of haNK cells. While there were only minor differences in the percentage of cells expressing a given marker, substantial differences in the levels of expression were observed, as determined by MFI. Compared with NK VV donors, haNK cells had a 20-fold higher MFI of CD56 (Fig. 5A), 2.9-fold higher expression of DNAM-1 (Fig. 5B), and 1.8-fold higher expression of NKG2D (Fig. 5C). There was no difference in perforin expression between NK cells and haNK cells (Fig. 5D). The mean MFI of CD16 was 1.5-fold higher in VV donors compared with FF donors and haNK cells (Fig. 5E).

\section{haNK Cell-Mediated ADCC of Chordoma Cells With Cetuximab}

To examine the potential utility of haNK cells for cetuximab therapy for chordoma, we performed an in vitro assay for cetuximab-mediated ADCC using haNK cells as effectors (Fig. 6A). Lysis by haNK cells with the isotype 

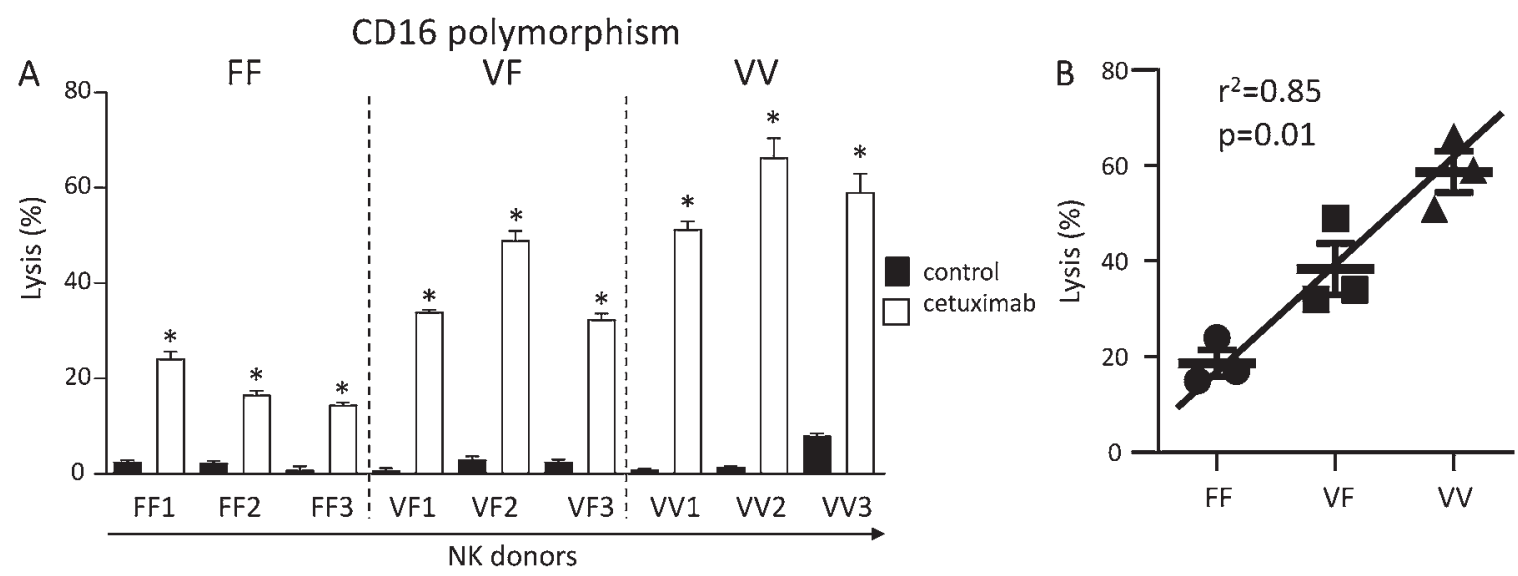

FIG. 4. Cetuximab-mediated ADCC by CD16 polymorphism-genotyped NK cells. A: ADCC assays were performed with UMChor1, using NK cells from $3 \mathrm{FF}, 3 \mathrm{VF}$, and $3 \mathrm{VV}$ healthy donors at an $\mathrm{E} / \mathrm{T}$ ratio of 10:1. Indicated groups were incubated with cetuximab. B: Correlation of cetuximab-mediated ADCC with NK cells from 3 FF, 3 VF, and 3 VV donors. * $p<0.05$, Student t-test. Error bars indicate mean \pm standard deviation for triplicate measurements.
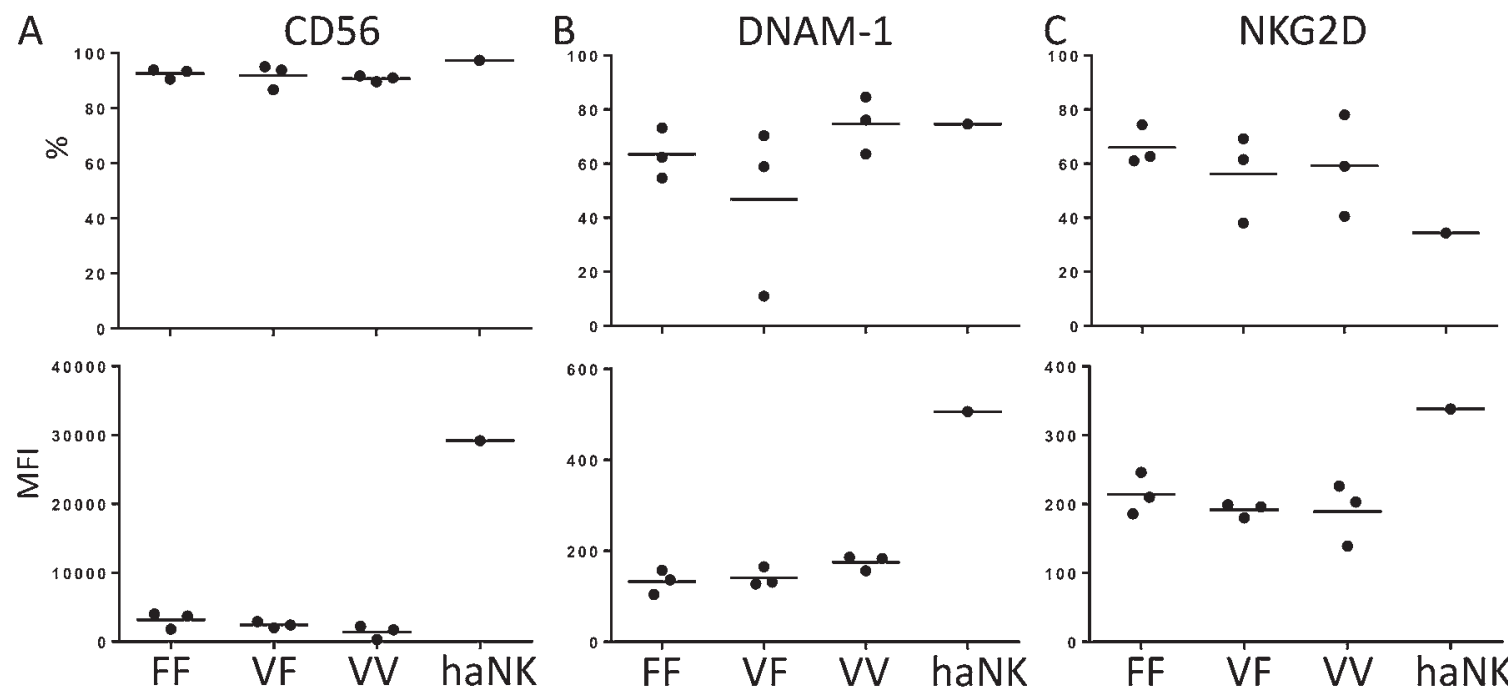

D
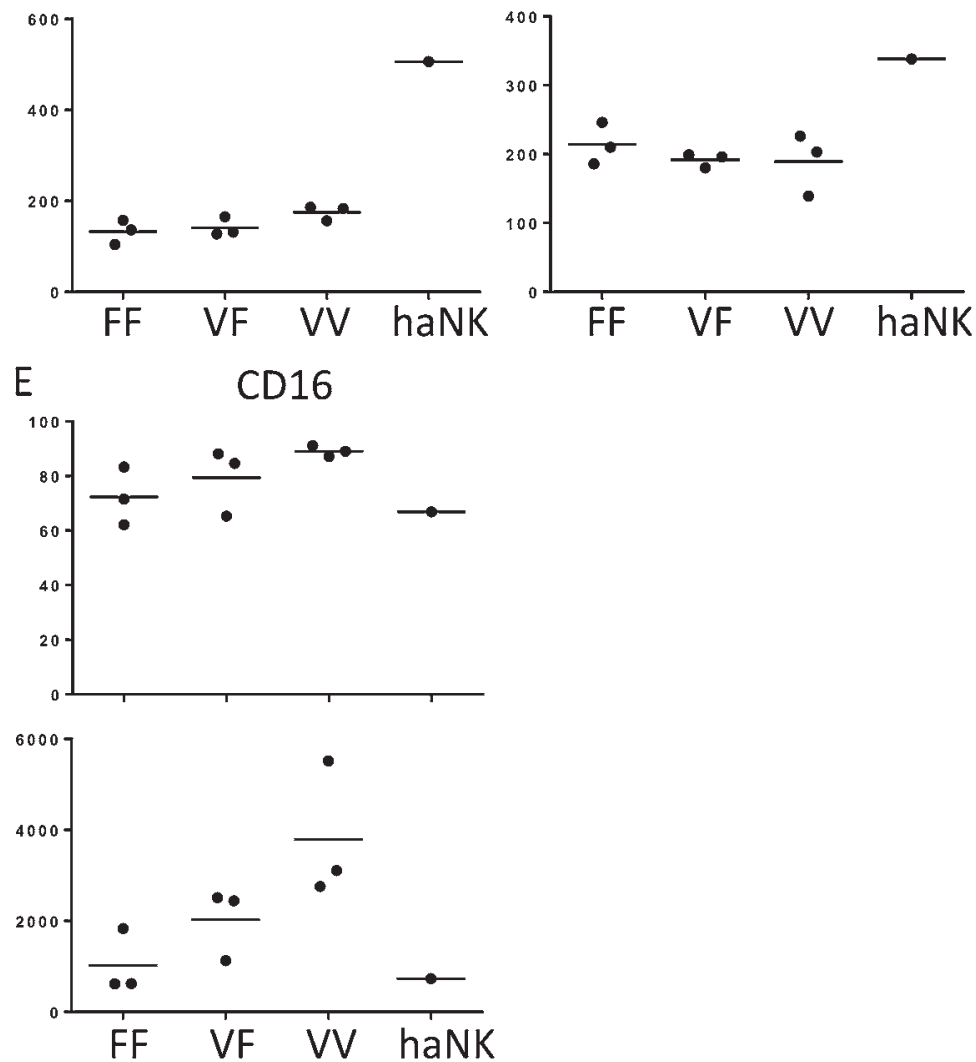

FIG. 5. The phenotype of CD16 polymorphism-genotyped NK cells and haNK cells. Expression levels of CD56 (A), DNAM-1 (B), NKG2D (C), perforin (D), and CD16 (E) of NK cells from 3 FF, 3 VF, 3 VV healthy donors and haNK cells. Numbers indicate percentage of positive cells (upper) and MFI (lower). Bars indicate the mean. 

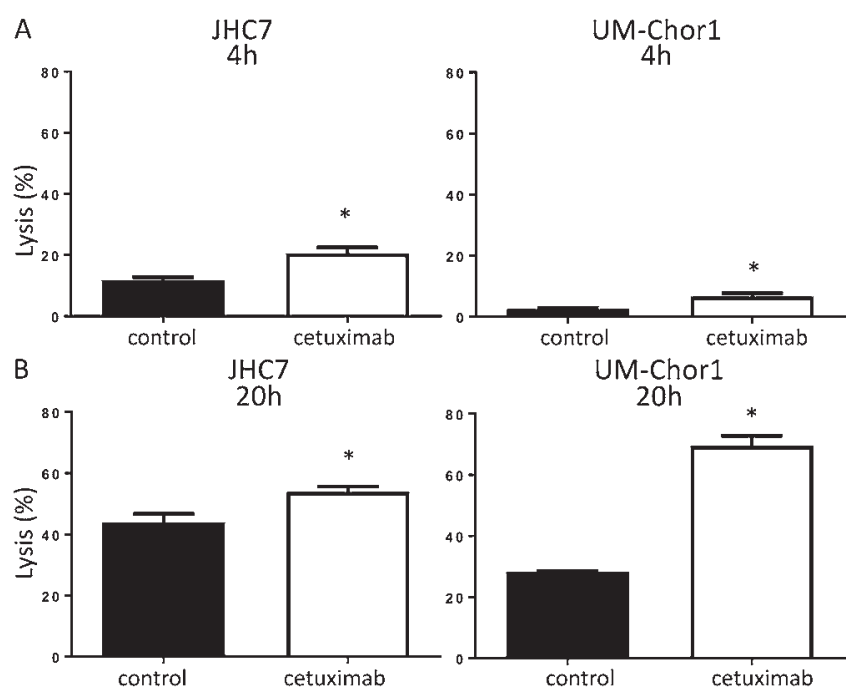

FIG. 6. Cetuximab increased haNK cell lysis via ADCC in chordoma cell lines. ADCC assays were performed with 2 chordoma cell lines, using haNK cells as effector cells at an E/T ratio of 20:1 for 4 hours $(A)$ and 20 hours (B). Indicated groups were incubated with cetuximab and/or anti-CD16 antibody. ${ }^{*} p<0.01$, Student t-test. Error bars indicate mean \pm standard deviation for triplicate measurements. This experiment was repeated at least 2 times with similar results.

control was $11.8 \%$ of JHC7 cells and $2.6 \%$ of UM-Chor1 cells. Cetuximab significantly enhanced haNK cell lysis compared with isotype control in both JHC7 (1.7-fold, p $<0.01)$ and UM-Chorl cells (2.6-fold, $\mathrm{p}<0.01)$. The addition of CD16 neutralizing antibody inhibited cetuximabenhanced haNK cell lysis in both JHC7 and UM-Chor1 cell lines (data not shown). As NK cells have previously been shown to be "serial killers"- that is, 1 NK cell can lyse up to 5 target cells $\mathrm{S}^{3,41}-20$-hour ${ }^{111}$ In-release assays were also performed (Fig. 6B). In those tests, lysis of the 2 chordoma cell lines was markedly greater. These results indicate that haNK cells induce ADCC via cetuximab in chordoma cells. To determine relative affinities, we next compared the ability of cetuximab to inhibit the binding of FITC-conjugated CD16 mAb to CD16 polymorphismgenotyped healthy-donor NK cells and haNK cells (Fig. 7A). A 50\% inhibition of CD16 antibody binding to NK cells from $4 \mathrm{FF}$ donors was achieved with $220 \mu \mathrm{g} / \mathrm{ml}$ of cetuximab. Compared with FF donors, a 4.5-fold lower (49.2 $\mu \mathrm{g} / \mathrm{ml})$ and 2.8 -fold lower $(80 \mu \mathrm{g} / \mathrm{ml})$ concentration of cetuximab showed a 50\% inhibition of CD16 antibody binding to healthy NK cells from a VV donor and haNK cells, respectively (Fig. 7B). These results show that both NK cells expressing Fc $\gamma$ RIIIa-158 VV and haNK cells bind cetuximab with higher affinity than NK cells expressing Fc $\gamma$ RIIIa-158 FF.

\section{Discussion}

Based on preclinical evidence of the role of EGFR in chordoma pathogenesis and immunohistochemical evidence that over $70 \%$ of chordoma specimens express EGFR,${ }^{34}$ several clinical trials targeting EGFR have been undertaken in chordoma patients. ${ }^{17}$ Because these trials were not randomized or well controlled, however, no con- sensus has been reached concerning the therapeutic benefit of EGFR inhibition in chordoma. In 2 separate case reports, the combination of the EGFR mAb cetuximab and gefitinib, a tyrosine kinase inhibitor of EGFR, demonstrated partial radiographically defined responses. ${ }^{13,19}$ However, the potential of cetuximab-induced ADCC in chordoma was not directly examined. Here, we showed that cetuximab markedly and significantly increases NK cell lysis via ADCC in 4 of 4 chordoma cell lines (Fig. $3)$. Moreover, NK cells obtained from healthy donors carrying FCGR3A-158 VV induced higher cetuximab-mediated ADCC lysis in chordoma (Fig. 4). Previous in vitro studies have indicated that the FcyRIIIa-158 VV phenotype of NK cells enhances the affinity of CD16 to IgG1 $1{ }^{14}$ inducing ADCC mediated via IgG1 mAb in several types of cancer cell lines. ${ }^{8,14,28}$ Some clinical studies have also shown that Fc $\gamma$ RIIIa polymorphisms of NK cells correlated with response to IgG1 mAb therapy. Musolino et al. reported that patients with metastatic breast cancer who had FCGR2A-131 histidine $(\mathrm{H}) / \mathrm{H}$ and/or FCGR3A-158 VV genotypes had a significantly better objective response rate and progression-free survival with trastuzumab therapy than patients with neither genotype. ${ }^{28}$ In a study of 49 patients with follicular lymphoma, FCGR $3 A-158 \mathrm{VV}$ patients had an improved response to rituximab. ${ }^{6}$ Three retrospective studies in metastatic colorectal cancer patients treated with cetuximab reported that $\mathrm{VV}$ is the most beneficial FCGR3A-158 genotype., ${ }^{4,10,32}$ Taken together, our observations indicate that cetuximab has potential clinical benefit for chordoma patients, especially in those $14 \%$ of patients with the FCGR3A-158 VV genotype or in combination with haNK cell infusion.

Although ADCC induction can be observed in in vitro models, clinical translation raises some obstacles. First, recruiting sufficient numbers of functionally active NK cells to target tumor tissues is technically challenging since they represent only $10 \%$ of lymphocytes and are often dysfunctional in a cancer-induced immunosuppressive environment. ${ }^{9}$ Moreover, chemotherapy and radiation therapy, first-line treatment for metastatic and/or advanced chordoma, could also reduce the number and activity of lymphocytes. Adoptive NK cell therapies have been developed to supply sufficient numbers of functional NK cells for patients. The cytotoxic NK-92 cell line was generated for adoptive transfer therapy from a 50-year-old man with progressive non-Hodgkin's lymphoma. Four Phase I trials in different malignancies have been conducted using irradiated NK-92 cells. The infusions were well tolerated, and clinical responses were observed in patients with hematological malignancies, melanoma, lung cancer, and kidney cancers. Since NK-92 cells do not express the Fc $\gamma$ RIIIa receptor, they cannot mediate ADCC. The NK cell line designated haNK was established by inducing high-affinity CD16 V158 Fc $\gamma$ RIIIa receptor to NK-92 cells. ${ }^{15}$ Since only approximately $14 \%$ of the population is homozygous for the high-affinity Fc $\gamma \mathrm{RIII}$ receptor $(F C G R 3 A-158 \mathrm{VV}),{ }^{18,20}$ there is a clear rationale for infusing haNK cells into patients who carry the genotype of the low- or intermediateaffinity Fc $\gamma$ RIIIa receptor to maximize $m A b$ efficacy. Our results show that haNK cells have a 2.8-fold higher affinity to cetuximab than NK cells from healthy donors carrying 


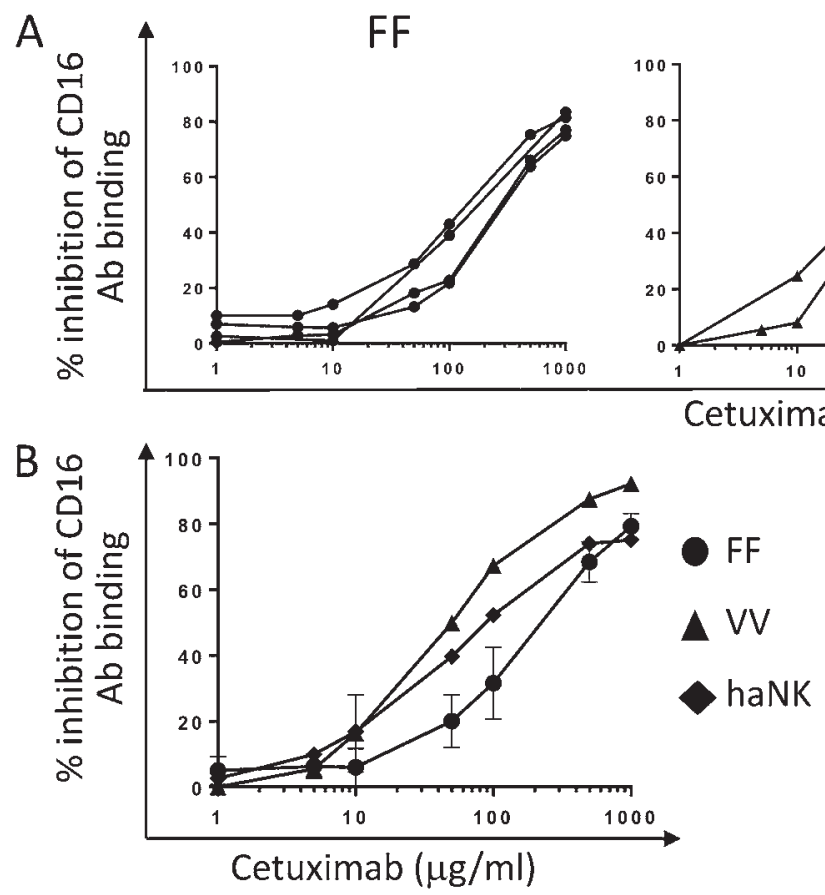

FIG. 7. CD16 affinity to cetuximab of NK cells versus haNK cells. Natural killer cells from $4 \mathrm{FF}$ and $2 \mathrm{VV}$ healthy donors and haNK cells were incubated with varying concentrations of cetuximab, followed by FITC-conjugated CD16 antibody. Percentage inhibition of CD16 mAb binding was calculated as described in Methods. A: Percentages of inhibition of CD16 mAb binding shown by each donor. B: The mean percentage inhibition of CD16 mAb binding.

the FCGR3A-158 FF genotype (Fig. 7B). Consistent with their high cetuximab-binding ability, haNK cells significantly induced ADCC via cetuximab in chordoma cells (Fig. 6). Moreover, since $10^{9}-10^{10}$ irradiated NK-92 cells were safely administered to cancer patients, the potential for similar levels of adoptive transfer of irradiated haNK cells exists, even in patients whose endogenous NK cells express the VV phenotype.

NK-92 cells have been shown to express large numbers of activating receptors such as NKp30, NKp46, and NKG2D. ${ }^{22}$ NKG2D and DNAM-1 are the best-characterized activating NK cell receptors implicated in the immune response against cancers. Both receptors recognize their ligands expressed on tumor cells and induce target cell lysis. ${ }^{27}$ Our data show that haNK cells, as compared with normal NK cells, have higher expressions of NKG2D and DNAM-1 according to MFI (Fig. 5A and B), indicating a greater ability to recognize and lyse tumor cells. Without cetuximab, NK cells from healthy donors lysed chordoma cells at extremely low levels (Figs. 3 and 4). In contrast, haNK cells induced greater lysis of chordoma cells without cetuximab (Fig. 6B).

\section{Conclusions}

Here we show for the first time that cetuximab can induce ADCC in chordoma cells, whereas chordoma cells cannot be killed in significant numbers by NK cells alone. Moreover, NK cells that express Fc $\gamma$ RIIIa-158 VV induced higher cetuximab-mediated ADCC of chordoma cells. An engineered NK-92 cell line transduced with haNK cells bound cetuximab with high affinity, resulting in haNK cell-induced ADCC via cetuximab in chordoma cells. Our results also indicate that cetuximab therapy could lead to a better clinical outcome for chordoma patients who have NK cells expressing the CD16 V158 Fc $\gamma$ RIIIa receptor allele. Adaptively transferred, irradiated haNK cells could provide sufficient numbers of functional NK cells for all chordoma patients and could functionally convert FCGR3A-158 FF carriers to VV carriers. Our findings provide the rationale for cetuximab plus irradiated haNK cell-mediated immunotherapy for clinical benefit in patients with chordoma.

\section{Acknowledgments}

We thank Marion Taylor and Michelle Padget for excellent technical assistance and Bonnie L. Casey and Debra Weingarten for their editorial assistance in the preparation of this manuscript.

This research was supported by the Intramural Research Program of the Center for Cancer Research, National Cancer Institute, National Institutes of Health, as well as through a Cooperative Research and Development Agreement (CRADA) between NantBioScience and the National Cancer Institute.

\section{References}

1. Anegón I, Cuturi MC, Trinchieri G, Perussia B: Interaction of Fc receptor (CD16) ligands induces transcription of interleukin 2 receptor $(C D 25)$ and lymphokine genes and expression of their products in human natural killer cells. J Exp Med 167:452-472, 1988

2. Arai S, Meagher R, Swearingen M, Myint H, Rich E, Martinson J, et al: Infusion of the allogeneic cell line NK-92 in patients with advanced renal cell cancer or melanoma: a phase I trial. Cytotherapy 10:625-632, 2008 
3. Bhat R, Watzl C: Serial killing of tumor cells by human natural killer cells-enhancement by therapeutic antibodies. PLoS One 2:e326, 2007

4. Bibeau F, Lopez-Crapez E, Di Fiore F, Thezenas S, Ychou M, Blanchard F, et al: Impact of Fc $\gamma$ RIIa-Fc $\gamma$ RIIIa polymorphisms and KRAS mutations on the clinical outcome of patients with metastatic colorectal cancer treated with cetuximab plus irinotecan. J Clin Oncol 27:1122-1129, 2009

5. Boyerinas B, Jochems C, Fantini M, Heery CR, Gulley JL, Tsang KY, et al: Antibody-dependent cellular cytotoxicity activity of a novel anti-PD-L1 antibody avelumab (MSB0010718C) on human tumor cells. Cancer Immunol Res 3:1148-1157, 2015

6. Cartron G, Dacheux L, Salles G, Solal-Celigny P, Bardos P, Colombat $P$, et al: Therapeutic activity of humanized antiCD20 monoclonal antibody and polymorphism in IgG Fc receptor Fc $\gamma$ RIIIIa gene. Blood 99:754-758, 2002

7. Chugh R, Tawbi H, Lucas DR, Biermann JS, Schuetze SM, Baker LH: Chordoma: the nonsarcoma primary bone tumor. Oncologist 12:1344-1350, 2007

8. Dall'Ozzo S, Tartas S, Paintaud G, Cartron G, Colombat P, Bardos P, et al: Rituximab-dependent cytotoxicity by natural killer cells: influence of FCGR3A polymorphism on the concentration-effect relationship. Cancer Res 64:4664-4669, 2004

9. de Souza AP, Bonorino C: Tumor immunosuppressive environment: effects on tumor-specific and nontumor antigen immune responses. Expert Rev Anticancer Ther 9:1317-1332, 2009

10. Etienne-Grimaldi MC, Bennouna J, Formento JL, Douillard JY, Francoual M, Hennebelle I, et al: Multifactorial pharmacogenetic analysis in colorectal cancer patients receiving 5-fluorouracil-based therapy together with cetuximab-irinotecan. Br J Clin Pharmacol 73:776-785, 2012

11. Fujii R, Friedman ER, Richards J, Tsang KY, Heery CR, Schlom J, et al: Enhanced killing of chordoma cells by antibody-dependent cell-mediated cytotoxicity employing the novel anti-PD-L1 antibody avelumab. Oncotarget 7:3349833511, 2016

12. Hildebrandt B, le Coutre P, Nicolaou A, Köble K, Riess H, Dörken B: Cetuximab: appraisal of a novel drug against colorectal cancer. Recent Results Cancer Res 176:135-143, 2007

13. Hof H, Welzel T, Debus J: Effectiveness of cetuximab/gefitinib in the therapy of a sacral chordoma. Onkologie 29:572574,2006

14. Jochems C, Hodge JW, Fantini M, Fujii R, Morillon YM II, Greiner JW, et al: An NK cell line (haNK) expressing high, levels of granzyme and engineered to express the high affinity CD16 allele. Oncotarget 7:86359-86373, 2016

15. Klingemann H, Boissel L, Toneguzzo F: Natural killer cells for immunotherapy - advantages of the NK-92 cell line over blood NK cells. Front Immunol 7:91, 2016

16. Koene HR, Kleijer M, Algra J, Roos D, von dem Borne AE, de Haas M: Fc $\gamma$ RIIIa-158V/F polymorphism influences the binding of IgG by natural killer cell Fc $\gamma$ RIIIa, independently of the Fc $\gamma$ RIIIa-48L/R/H phenotype. Blood 90:1109-1114, 1997

17. Lebellec L, Aubert S, Zaïri F, Ryckewaert T, Chauffert B, Penel N: Molecular targeted therapies in advanced or metastatic chordoma patients: facts and hypotheses. Crit Rev Oncol Hematol 95:125-131, 2015

18. Lehrnbecher T, Foster CB, Zhu S, Leitman SF, Goldin LR, Huppi K, et al: Variant genotypes of the low-affinity Fc $\gamma$ receptors in two control populations and a review of lowaffinity Fc $\gamma$ receptor polymorphisms in control and disease populations. Blood 94:4220-4232, 1999

19. Lindén O, Stenberg L, Kjellén E: Regression of cervical spinal cord compression in a patient with chordoma following treatment with cetuximab and gefitinib. Acta Oncol 48:158159,2009

20. Liu G, Tu D, Lewis M, Cheng D, Sullivan LA, Chen Z, et al: $\mathrm{Fc}-\gamma$ receptor polymorphisms, cetuximab therapy, and survival in the NCIC CTG CO.17 trial of colorectal cancer. Clin Cancer Res 22:2435-2444, 2016

21. López-Albaitero A, Lee SC, Morgan S, Grandis JR, Gooding WE, Ferrone $S$, et al: Role of polymorphic Fc gamma receptor IIIa and EGFR expression level in cetuximab mediated, NK cell dependent in vitro cytotoxicity of head and neck squamous cell carcinoma cells. Cancer Immunol Immunother 58:1853-1864, 2009

22. Maki G, Klingemann HG, Martinson JA, Tam YK: Factors regulating the cytotoxic activity of the human natural killer cell line, NK-92. J Hematother Stem Cell Res 10:369-383, 2001

23. Matlawska-Wasowska K, Gale JM, Nickl CK, Khalili P, Shirley B, Wilson BS, et al: Pyrosequencing for classification of human Fc $\gamma$ RIIIA allotypes: a comparison with PCR-based techniques. Mol Diagn Ther 18:665-673, 2014

24. McMaster ML, Goldstein AM, Bromley CM, Ishibe N, Parry DM: Chordoma: incidence and survival patterns in the United States, 1973-1995. Cancer Causes Control 12:1-11, 2001

25. Mellor JD, Brown MP, Irving HR, Zalcberg JR, Dobrovic A: A critical review of the role of Fc gamma receptor polymorphisms in the response to monoclonal antibodies in cancer. $\mathbf{J}$ Hematol Oncol 6:1, 2013

26. Monteverde M, Milano G, Strola G, Maffi M, Lattanzio L, Vivenza D, et al: The relevance of ADCC for EGFR targeting: A review of the literature and a clinically-applicable method of assessment in patients. Crit Rev Oncol Hematol 95:179-190, 2015

27. Morvan MG, Lanier LL: NK cells and cancer: you can teach innate cells new tricks. Nat Rev Cancer 16:7-19, 2016

28. Musolino A, Naldi N, Bortesi B, Pezzuolo D, Capelletti M, Missale $\mathrm{G}$, et al: Immunoglobulin $\mathrm{G}$ fragment $\mathrm{C}$ receptor polymorphisms and clinical efficacy of trastuzumab-based therapy in patients with HER-2/neu-positive metastatic breast cancer. J Clin Oncol 26:1789-1796, 2008

29. Negri FV, Musolino A, Naldi N, Bortesi B, Missale G, Laccabue D, et al: Role of immunoglobulin $\mathrm{G}$ fragment $\mathrm{C}$ receptor polymorphism-mediated antibody-dependant cellular cytotoxicity in colorectal cancer treated with cetuximab therapy. Pharmacogenomics J 14:14-19, 2014

30. Oboshi W, Watanabe T, Matsuyama Y, Kobara A, Yukimasa N, Ueno I, et al: The influence of NK cell-mediated ADCC: Structure and expression of the CD16 molecule differ among Fc $\gamma$ RIIIa-V158F genotypes in healthy Japanese subjects. Hum Immunol 77:165-171, 2016

31. Ravetch JV, Perussia B: Alternative membrane forms of Fc $\gamma$ RIII(CD16) on human natural killer cells and neutrophils. Cell type-specific expression of two genes that differ in single nucleotide substitutions. J Exp Med 170:481-497, 1989

32. Rodríguez J, Zarate R, Bandres E, Boni V, Hernández A, Sola JJ, et al: Fc gamma receptor polymorphisms as predictive markers of Cetuximab efficacy in epidermal growth factor receptor downstream-mutated metastatic colorectal cancer. Eur J Cancer 48:1774-1780, 2012

33. Scheipl S, Barnard M, Cottone L, Jorgensen M, Drewry DH, Zuercher WJ, et al: EGFR inhibitors identified as a potential treatment for chordoma in a focused compound screen. $\mathbf{J}$ Pathol 239:320-334, 2016

34. Shalaby A, Presneau N, Ye H, Halai D, Berisha F, Idowu B, et al: The role of epidermal growth factor receptor in chordoma pathogenesis: a potential therapeutic target. J Pathol 223:336-346, 2011

35. Siu IM, Ruzevick J, Zhao Q, Connis N, Jiao Y, Bettegowda C, et al: Erlotinib inhibits growth of a patient-derived chordoma xenograft. PLoS One 8:e78895, 2013 
36. Stacchiotti S, Sommer J: Building a global consensus approach to chordoma: a position paper from the medical and patient community. Lancet Oncol 16:e71-e83, 2015

37. Tamborini E, Virdis E, Negri T, Orsenigo M, Brich S, Conca $\mathrm{E}$, et al: Analysis of receptor tyrosine kinases (RTKs) and downstream pathways in chordomas. Neuro Oncol 12:776789,2010

38. Taylor RJ, Chan SL, Wood A, Voskens CJ, Wolf JS, Lin W, et al: Fc $\gamma$ RIIIa polymorphisms and cetuximab induced cytotoxicity in squamous cell carcinoma of the head and neck. Cancer Immunol Immunother 58:997-1006, 2009

39. Tonn T, Schwabe D, Klingemann HG, Becker S, Esser R, Koehl U, et al: Treatment of patients with advanced cancer with the natural killer cell line NK-92. Cytotherapy 15:1563-1570, 2013

40. Treon SP, Hansen M, Branagan AR, Verselis S, Emmanouilides C, Kimby E, et al: Polymorphisms in FcgammaRIIIA (CD16) receptor expression are associated with clinical response to rituximab in Waldenström's macroglobulinemia. J Clin Oncol 23:474-481, 2005

41. Vanherberghen B, Olofsson PE, Forslund E, Sternberg-Simon M, Khorshidi MA, Pacouret S, et al: Classification of human natural killer cells based on migration behavior and cytotoxic response. Blood 121:1326-1334, 2013

42. Walcott BP, Nahed BV, Mohyeldin A, Coumans JV, Kahle KT, Ferreira MJ: Chordoma: current concepts, management, and future directions. Lancet Oncol 13:e69-e76, 2012

43. Weinberger PM, Yu Z, Kowalski D, Joe J, Manger P, Psyrri A, et al: Differential expression of epidermal growth factor receptor, c-Met, and HER2/neu in chordoma compared with 17 other malignancies. Arch Otolaryngol Head Neck Surg 131:707-711, 2005
44. Weng WK, Levy R: Genetic polymorphism of the inhibitory $\mathrm{IgG} \mathrm{F}$ c receptor FcgammaRIIb is not associated with clinical outcome in patients with follicular lymphoma treated with rituximab. Leuk Lymphoma 50:723-727, 2009

45. Zimmermann H, Weiland T, Nourse JP, Gandhi MK, Reinke $\mathrm{P}$, Neuhaus R, et al: Fc $\gamma$-receptor IIIA polymorphism $\mathrm{p} .158 \mathrm{~F}$ has no negative predictive impact on rituximab therapy with and without sequential chemotherapy in CD20-positive posttransplant lymphoproliferative disorder. J Immunol Res 2014:264723, 2014

\section{Disclosures}

The authors report no conflict of interest concerning the materials or methods used in this study or the findings specified in this paper.

\section{Author Contributions}

Conception and design: Hodge, Fujii. Acquisition of data: Hodge, Fujii. Analysis and interpretation of data: Hodge, Fujii. Drafting the article: all authors. Critically revising the article: all authors. Reviewed submitted version of manuscript: all authors. Approved the final version of the manuscript on behalf of all authors: Hodge. Statistical analysis: Hodge, Fujii. Administrative/techni$\mathrm{cal} /$ material support: Hodge. Study supervision: Hodge.

\section{Correspondence}

James W. Hodge, Laboratory of Tumor Immunology and Biology, Center for Cancer Research, National Cancer Institute, National Institutes of Health, 10 Center Dr., Rm. 8B13, Bethesda, MD 20892.email: jh241d@nih.gov. 